\title{
Resistance of Gastrointestinal Nematodes to Anthelmintics in Sheep (Ovis aries)
}

\author{
Vanete Thomaz-Soccol $^{1 *}$, Felipe Pohl de Souza ${ }^{2}$, Cristina Sotomaior ${ }^{2}$, Edilene Alcântara \\ Castro $^{1}$, Viviane Milczewski ${ }^{3}$, Giovani Mocelin ${ }^{4}$ and Maria do Carmo Pessoa e Silva ${ }^{5}$ \\ ${ }^{I}$ Departamento de Parasitologia Animal e Patologia Básica; Centro Politécnico; Universidade Federal do Paraná; \\ Jardim das Américas; vasoccol@ ufpr.br; 81530-320; Curitiba - PR - Brazil. ${ }^{2}$ Pontifícia Universidade Católica do \\ Paraná; Curitiba - PR - Brazil. ${ }^{3}$ Faculdades Integradas "Espírita"; Curitiba - PR - Brazil. ${ }^{4}$ Departamento de \\ Engenharia Química; Universidade Federal do Paraná; Curitiba - PR - Brazil. ${ }^{5}$ Secretaria de Agricultura do \\ Estado do Paraná; Curitiba - PR - Brazil
}

\begin{abstract}
The fecal egg count reduction test (FECRT) was used in a survey for anthelmintic resistance in 42 sheep farms, in five different regions in Paraná State, Brazil between July 1996 - July 2000. Animals with natural infection were tested. Five drugs were used individually or in combination - benzimidazole, imidazothiazole, ivermectin, milbemicina and closantel. Results showed that the prevalence of resistance to all anthelmintic was as high as $88.1 \%$ for benzimidazoles (oxfendazole), $78.6 \%$ for ivermectin, $56.4 \%$ for closantel , $38.7 \%$ for closantel + oxfendazole, 38\% for levamisole, and $23.6 \%$ for moxidectin. There was multiple resistance in all tested farms. The most important infective larvae recovered from culture were Haemonchus contortus and Trichostrongylus colubriformis. The failure of the existing drugs in the State of Paraná is considered an important issue. Some proposals to improve the situation are suggested which include a change of attitude on anthelmintic use by sheepherders, veterinarians and sanitary authorities.
\end{abstract}

Key Words: Gastrointestinal parasite, sheep nematode, Ovis aries, anthelmintic resistance, FECRT

\section{INTRODUCTION}

The resistance to anthelmintic drugs becomes a serious problem in countries with small ruminants industry. There are many reports on anthelmintic resistance from several parts of the world and the problem affects the different anthelmintic classes, for several families of helminths (Sangster, 1999, Zajac and Gipson, 2000).

In the South Hemisphere the resistance problem got epidemic proportions at the beginning of the nineties. The FAO (Food and Agriculture Organization), concerned with the problem, supported a study to detect the resistance level to anthelmintic in Argentina, Brazil (State of Rio Grande do Sul), Paraguay and Uruguay, with favorable climatic conditions for the development of parasites and with an important sheep industry (Waller et al., 1996).

In Brazil, anthelmintic resistance in sheep was found in Ceará State (Vieira et al., 1992), and in Rio Grande do Sul State (Echevarria and Pinheiro, 1989, Echevarria and Trindade, 1989, Souza et al., 1993, Echevarria et al., 1996, Farias et al., 1997). In Paraná State, Southern Brazil, the sheep industry didn't have much importance,

*Author for correspondence 
economically, until recent years. Just in the eighties they established Suffolk and Hampshire Down sheep breeds. In 1992, 250,000 sheep were brought to the State and distributed into small farms with a management system that allowed a high number of sheep in small but high value areas. This high intensive husbandry system of meat sheep production in Paraná State has as main characteristic, a high stocking rate and consequently, high helminths eggs contamination in pasture. The gastrointestinal nematodes control plays an important role in sheep breeding. Actually, the control is based only on suppressive anthelmintic treatment which is done every 15 to 30 days and has led to a crisis situation of anthelmintic resistance. The problem can be measured by a high mortality rate in weaned lambs and adult lactating ewes. In a initial survey Soccol et al., (1996) and Cunha Filho et al., (1998) found the resistance problem in several sheep farms. Thus, the main goal of this work was to study the anthelmintic efficacy in sheep in five regions of Paraná, South of Brazil.

\section{MATERIAL AND METHODS}

\section{Animals and management}

A total of 42 sheep farms were examined during this investigation. All sheep farms are private owned with an animal population varying between 50 and 250 heads. However, some of the farms had only pure breed animals (Suffolk, Hampshire, Ile de France, Texel) and others worked with crossbreed animals. All of them work with very close management systems. They were housed overnight in raised floor pens, where they were offered water ad libitum, salt or mineral blocks. The animals grazed all day long or received a concentrated complement at night. The routine procedures for worm control on all farms were to drench the sheep from 6 to 12 times each year. Some farms practiced rotational of drug groups, but it generally depended on the price of anthelmintic. The only difference between the pure breed and cross breed farms is the anthelmintic price: the first used a high cost anthelmintic (ivermectin, moxidectin) and the second usually a cheaper one (benzimidazole, levamisole).

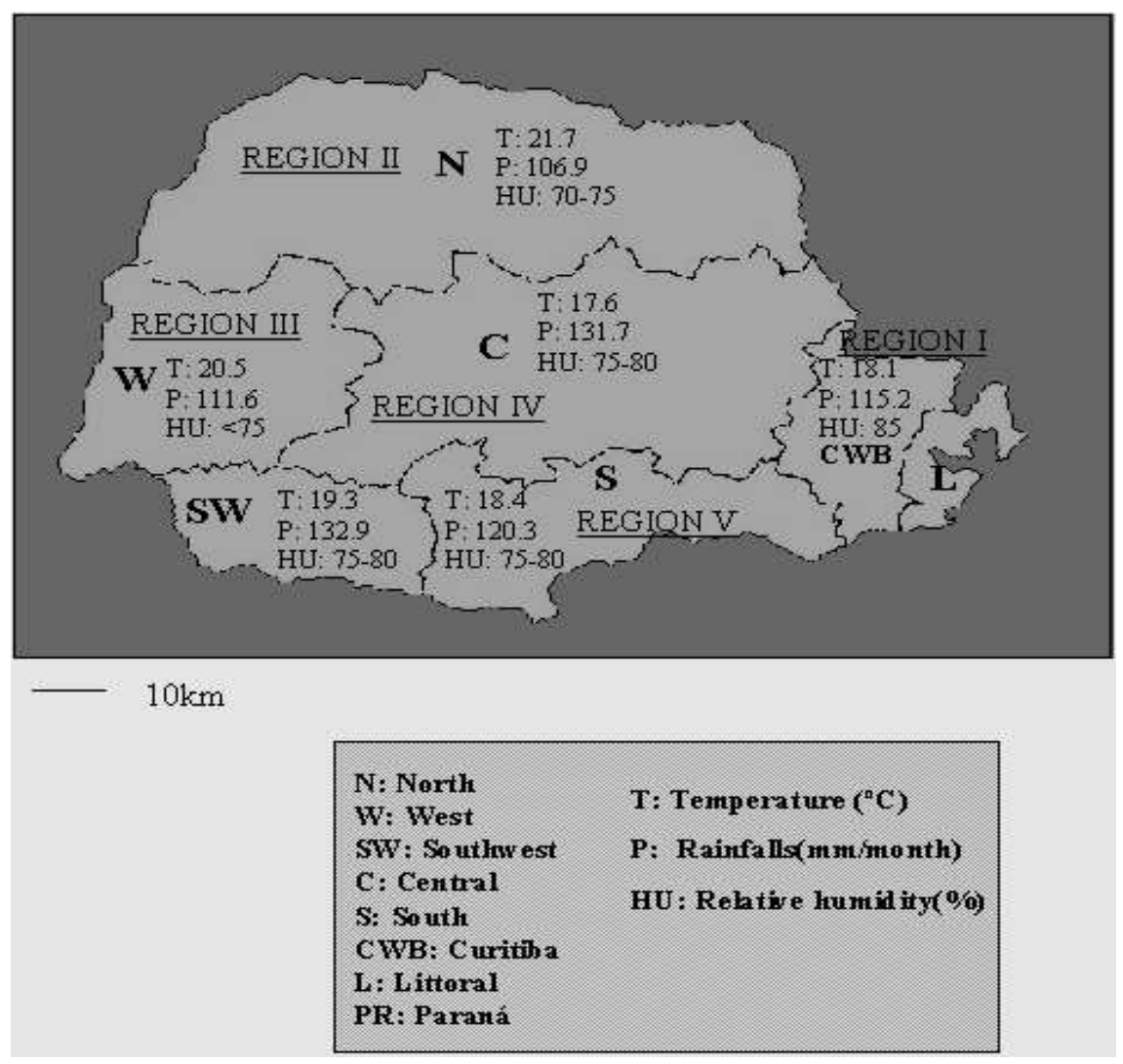

Figure 1- Location of sheep farms in Paraná State, South Brazil, screened for anthelmintic resistance. 
The criteria for the selection was randomly done in farms where:

a) the number of animals were above 50 .

b) conditions to weight each animal in order to apply the correct dosage of anthelmintic;

c) fecal eggs counts were to be more than 500 EPG (Eggs Per Gram of faeces);

\section{Climatic Regions}

The selected farms were located in five different climatic regions in Paraná (Fig. 1). Tropical and subtropical conditions prevail in the regions with high rainfall levels (IAPR doc.18, 1994). The coastal region with high humidity was not chosen because there was no property with a significant number of sheep.

In the other regions the properties are distributed as following:

a) REGION I - Sub-Tropical with humidity and frost, 13 properties distributed in 7 county;

b) REGION II - Tropical semi-humid, 11 properties distributed in 4 county;

c) REGION III - Sub-Tropical with mild humidity, 7 properties distributed in 3 county;

d) REGION IV - Sub-Tropical high-humid with frost, 10 properties distributed in 4 county;

e) REGION V - Temperate humid (mild), 1 property in the municipality of Palmas.

\section{Field and Laboratory testing}

The Fecal Egg Count Reduction Test (FECRT) was conducted to detect the presence of anthelmintic resistance. The flocks were divided in homogeneous groups of 10 to 20 animals with similar age, weight and sex. The number of groups was related to the number of treatments and their number of associations to be tested. One untreated group was used as control reference. Once the animals were weighed, their faeces were collected and the animals were treated and marked. All samples were kept in cold boxes until they were sent to the laboratory (Biology Sciences Dept., Veterinarian Parasitology of Universidade Federal do Paraná). A sample collection was repeated fourteen days after first treatment using identical procedures as first collection.

FECRT (Fecal Egg Count Reduction Test) were determined following the method of the World Association for the Advancement of Veterinary Parasitology (WAAVP) (Coles et al., 1992). The RESO program calculated the reduction percentage. The resistance was suspected when the reduction percentage in nematodes eggs was lower than $95 \%$. The confidence level of $95 \%$ was less than $90 \%$. It was considered suspect if only one or two criteria were present.

Portions of individual fecal samples were within treatment and control groups for coproculture (7 days at $25^{\circ} \mathrm{C}$ ) (Roberts and O'Sullivan, 1950) and identification of third stage larvae (L3). One hundred larvae were counted and the results were expressed as the proportion (\%) of L3 recovered. Fecal egg counts were expressed as a percentage for each parasite species and the results were analyzed according to the RESO statistical package (provided by Dr. F. Echevarria from EMBRAPA-Bage, Brazil).

\section{Treatments}

On day 0 , tests with 5 different anthelmintics (Table 1) were carried out individually or in mixtures. The animals were treated with calculated dose for the heaviest in each group.

Table 1 - Anthelmintic and dosages used in the present work.

\begin{tabular}{|c|c|}
\hline ANTHELMINTIC & DOSAGES \\
\hline $\begin{array}{l}\text { 1. BENZIMIDAZOLES } \\
\text { Oxfendazole }(\mathrm{OXF})^{(1)}\end{array}$ & $15 \mathrm{mg} / \mathrm{kg}$ \\
\hline $\begin{array}{l}\text { 2. IMIDAZOTHIAZOLES } \\
\text { Levamisole (LEV) }^{(2 \mathrm{a})} \\
\text { 3.MACROCYCLIC } \\
\text { LACTONES }\end{array}$ & $7.5 \mathrm{mg} / \mathrm{kg}$ \\
\hline $\begin{array}{l}\text { Ivermectin }(\text { IVM) })^{(3)} \\
\text { Moxidectin }(\mathrm{MOX})^{(4)} \\
\text { 4.SALICILANILIDE }\end{array}$ & $\begin{array}{l}0.2 \mathrm{mg} / \mathrm{kg} \\
0.2 \mathrm{mg} / \mathrm{kg}\end{array}$ \\
\hline $\begin{array}{l}\text { Closantel }(\text { CLO })^{(5)} \\
5 . \text { MIXTURE } \\
(\mathrm{CLO}+\mathrm{BZ})\end{array}$ & $15 \mathrm{mg} / \mathrm{kg}$ \\
\hline $\begin{array}{l}\text { Closantel }^{(5 \mathrm{a}, \mathrm{b})} \\
\text { Oxfendazole }^{(1)}\end{array}$ & $\begin{array}{l}7.5 \mathrm{mg} / \mathrm{kg} \\
10 \mathrm{mg} / \mathrm{kg}\end{array}$ \\
\hline
\end{tabular}

1) Systamex Suspensão; 2) Ripercol - Cyanamid Quimica do Brasil Ltda.; 3) Ivomec Injetável - Merck Sharp and Dohme ME; 4) Cydectin - Cyanamid Química do Brasil Ltda.; 5 a) Closantel Fatec - Fatec S.A.; 5 b) Teczamida - Tecpar.

The anthelmintic doses were made based on literature (Waller et al., 1996) (in Brazil many anthelmintics are under dosage as benzimidazole used with $3.8 \mathrm{mg} \mathrm{kg}^{1}$ and Levamisole $5.8 \mathrm{mg} \mathrm{kg}$, Echevarria et al., 1996). 


\section{RESULTS}

Forty two farms with 2,274 animals were studied. In Region I, BZ's and IVM were applied in 13 properties, but only one and two showed sensitivity respectively. Resistance in five farms was detected to closantel single. The association CLO + BZ gave excellent results in 9 flocks (Table 2). Region II presented resistance to IVM in 9 of the 11 farms. MOX was efficient in all properties but CLO presented resistance in 3 of the 11 tested flocks. The BZ's presented resistance in 8 of 11 tested flocks The mixture CLO + BZ was efficient in five studied flocks (Table 2). Region III presented IVM with efficiency in 2 of the 7 studied flocks. The MOX reduced the infection in more than $95 \%$ of the occurrences in 4 farms and the CLO individually was efficient in 1 of the 6 farms. The mixture CLO + OXF was efficient for 3 of the 4 flocks (Table 2). In Region IV, IVM there were a few farms with results and only two out of ten farms were efficient. Closantel single or their mixtures with BZ presented the best results (Table 2). Region V had only one studied farm and all the tested products presented resistance (Table 2). When we analyzed the five regions we observed that $88.1 \%$ of the farms showed resistance to the BZ, $78.6 \%$ to IVM, 56.4 to closantel individually, $23.6 \%$ to MOX and $38.7 \%$ to the intermixture CLO + OXF (Table 3).

The parasite Haemonchus sp. was the most common Trichostrongylidae in sheep on all farms showing multiple types of resistance from different climatic regions. Others species recorded were Trichostrongylus sp, Cooperia sp., Oesophagostomum sp., Ostertagia sp. (Table 4). The parasite Haemonchus sp. was prevalent in the regions I, II and V. Trichostrongylus sp. was prevalent in the regions III and IV (Table 4).

Table 2 - Percentage of egg count reduction after treatment in 42 sheep farms in Region I (humid sub tropical with frost climate), Region II, (tropical semi-humid climate), Region III (mild humid sub-tropical climate), Region IV (humid sub-tropical with frost climate) and Region V (mild humid temperate climate) from Paraná State, south Brazil.

\begin{tabular}{|c|c|c|c|c|c|c|c|c|c|c|c|c|}
\hline \multirow[t]{3}{*}{ REGION } & \multicolumn{12}{|c|}{ ANTHELMINTICS } \\
\hline & \multicolumn{2}{|c|}{ IVM } & \multicolumn{2}{|c|}{ MOX } & \multicolumn{2}{|c|}{ LEV } & \multicolumn{2}{|c|}{ OXF } & \multicolumn{2}{|c|}{ CLO } & \multicolumn{2}{|c|}{ CLO+OXF } \\
\hline & $\mathbf{T}$ & $\mathbf{R}$ & $\mathbf{T}$ & $\mathbf{R}$ & $\mathbf{T}$ & $\mathbf{R}$ & $\mathbf{T}$ & $\mathbf{R}$ & $\mathbf{T}$ & $\mathbf{R}$ & $\mathbf{T}$ & $\mathbf{R}$ \\
\hline I & 13 & 11 & 12 & 4 & 13 & 7 & 13 & 12 & 12 & 5 & 11 & 2 \\
\hline II & 11 & 9 & 11 & 0 & 11 & 3 & 11 & 8 & 11 & 3 & 6 & 1 \\
\hline III & 7 & 5 & 6 & 2 & 7 & 0 & 7 & 7 & 6 & 5 & 4 & 1 \\
\hline IV & 10 & 8 & 9 & 3 & 10 & 4 & 10 & 7 & 10 & 3 & 10 & 2 \\
\hline V & 1 & 1 & 0 & 0 & 1 & 1 & 1 & 1 & 0 & 0 & 0 & 0 \\
\hline Total & 42 & 34 & 38 & 9 & 42 & 15 & 42 & 35 & 42 & 16 & 31 & 6 \\
\hline
\end{tabular}

$\mathbf{T}$ - number of test farms $\quad \mathbf{R}$ - number of farms with resistance

Table 3 - Percentage of resistance by different drugs when $95 \%$ egg reduction level was taken into consideration or the efficiency in 42 sheep flocks studied between July/1996 -July/2000 in the Paraná State, south Brazil.

\begin{tabular}{lc|cccc|cc}
\hline & & \multicolumn{5}{|c|}{ No. Resistant with FECRT } & \\
\hline ANTHEL- & $\begin{array}{c}\text { No. of } \\
\text { farms }\end{array}$ & $<\mathbf{5 0}$ & $\mathbf{5 1 - 9 0}$ & $\mathbf{9 1 - 9 4}$ & $\begin{array}{c}\text { No. with } \\
\text { suspected } \\
\text { resistant }\end{array}$ & $\begin{array}{c}\text { \% } \\
\text { RESISTANCE }\end{array}$ & $\begin{array}{c}\text { \%. of farms } \\
\text { SUSCEPTIBLE }\end{array}$ \\
\hline IVM & 42 & 16 & 14 & 1 & 2 & 78.6 & 21.4 \\
MOX & 38 & 0 & 6 & 2 & 1 & 23.6 & 76.4 \\
LEV & 42 & 2 & 10 & 3 & 1 & 38 & 62 \\
OXF & 42 & 19 & 13 & 3 & 2 & 88.1 & 11.9 \\
CLO & 39 & 2 & 4 & 10 & 6 & 56.4 & 43.6 \\
CLO+OXF & 31 & 0 & 4 & 3 & 5 & 38.7 & 61.3 \\
\hline
\end{tabular}


Table 4 - Identities and frequency of nematode genera involvement from larval cultures from faeces on sheep farms with resistance to different anthelmintic treatment from Paraná State, Brazil.

\begin{tabular}{l|c|c|c|c|c}
\hline \multirow{2}{*}{ PARASITES } & \multicolumn{4}{c}{ PERCENTAGE OF TOTAL NUMBER OF HELMINTHS LARVAE (L3) } \\
\cline { 2 - 6 } & REGION I & REGION II & REGION III & REGION IV & REGION V \\
\hline Haemonchus sp. & 39.5 & 60.5 & 37.7 & 29.1 & 72.8 \\
Trichostrongylus sp. & 28.9 & 6.2 & 50.1 & 43.9 & 5.4 \\
Ostertagia sp. & 25.4 & 2.7 & 0.03 & 24.3 & 20.5 \\
Cooperia sp. & 1.8 & 29.3 & 4.2 & 0.3 & 0.4 \\
Nematodirus sp. & 4.3 & 1.3 & 0 & 2.2 & 0.1 \\
Oesophagostomum sp. & 0 & 0 & 7.6 & 0 & 0 \\
\hline
\end{tabular}

\section{DISCUSSION}

The Paraná State is located between the parallels $23^{\circ}$ and $27^{\circ}$ south within the most critical circle of parasite infection. This climate region is the most favorable (high humidity and suitable temperature) for survival of free-living stages of the parasite (L3). Most of property owners in the State have followed a high number of drenches (more than 612 times year $\left.{ }^{-1}\right)$, changing the commercial product frequently, but not necessarily the chemical group's active ingredient in each application. In farms with pure breed, the sheep are drenched 1224 times year ${ }^{-1}$. This suppressive treatment using a high frequency of anthelmintic's applications is correlated with the breeding system. Sheep are bred in small farms or in small areas in large properties, both without separation of animals by category. Moreover, sheep farms rarely share the land with other animals therefore; this situation favors the continuous infection. Also, it favors the maintenance of a large larval population (L3) throughout the year. These conditions allow for the continuous re-infections and treatments are applied with high frequency. The high selection pressure leads to the development of resistant populations in a short time. Resistance is probably an inevitable consequence of a high number of anthelmintic applications (Dash et al. 1985, Sangster, 1999). The speed of the selection for resistance will be also influenced by other factors such as genetic inheritance resistence, biological traits (generation turnover, life cycle), proportion of population "in refuge" and operational factors, like the number of treatments per year, anthelmintic efficiency, drug rotation (Prichard, 1990, Echevarria et al., 1993, Sangster, 1999). In Paraná State $H$. contortus is the most prevalent parasite. The above mentioned conditions in the State could have been the cause for the fast manifestation of behavioral resistance. Resistance was present in $88.1 \%$ of benzimidazoles and $38 \%$ of levamizole. The results are similar to those observed by Nari et al, 1996, Maciel et al.,1996, Eddi et al., 1996 and Echevarria et al., 1996 in Uruguay, Paraguay, Argentina and Rio Grande do Sul South of Brazil, respectively. We observed $78.6 \%$ of farms with resistance to ivermectin. Similar results were reported by Maciel et al., 1996 in Paraguay. Paraná State is near to Paraguay and the management control systems of verminosis are very similar. Farmers in both countries use suppressive treatments and mostly use ivermectin due to the easiness of the product application as well as to the results obtained. Therefore, a fast resistance to this principle has installed itself and only when there was a defect on the product the sheep breeders became interested in the problem.

Another factor, which contributed to the appearing of the resistance, was the animal importation from regions where there was already resistance to benzimidazoles and levamizole. One example of this occurred where the sheep breeders and the State Officials imported a large number of animals without any concern of anthelmintic resistance; one farm from region III bought animals coming from the State of Rio Grande do Sul and only two weeks after their arrival in the State of Paraná, they were submitted to anthelmintic tests and presented resistance to all the proposed treatments. The problems in the State of Parana revealed that the resistance was imported and increased due to the management system applied in most of the farms. Later the resistance can be also exported with animals for reproduction (Vieira et al., 1989). Parasite infections in the sheep farms increased in a direct correlation with imports of animals for breeding purposes. Perez (1932) had concluded the fact above, revealing that this was an old problem. In this work we detected nematodes resistance to all the chemicals including the mixture of closantel 
+ oxifendazole and was recorded in two of the most important ovine nematode parasites in Paraná State, named Haemonchus sp. and Trichostrongylus sp. The presence of multiple resistance in all climatic regions of Paraná was observed, mainly in region I. The problem could be very serious for some of the sheep breeders that are looking for new genetic material in the State because animals for reproduction can carry with them a very high anthelmintic resistance in selected parasite populations.

\section{CONCLUSIONS}

a) These results provide further documentation of anthelmintic resistance in sheep in Paraná State, Brazil;

b) The gastrointestinal helminths resistance to anthelmintic in sheep was present in all farms tested;

c) Resistance to different genera of nematodes was detected in all tested flock;

d) Sheep resistance to anthelmintic was partially imported, however, the main factor of the development of the resistance were the frequent applications of chemicals in anthelmintic treatment used in the breeding system of the State;

e) The presence of multiple resistance to chemicals leads to the urgent need for developing an alternative gastrointestinal parasite control program, based on epidemiological dates and periodical post treatment faecal examination to monitor performance of individual anthelmintcs;

f) The creation of an official control program is important to avoid the spread of multi-resistant stock in the State and in the country.

g) Veterinarians and extensional personnel must increase their efforts to educate producers in techniques to reduce selection pressure for resistance as pasture rotation.

\section{ACKNOWLEDGEMENTS}

This survey was financially supported by Conselho Nacional de Pesquisa (CNPq), Fundação Araucária and Secretaria Estadual de Agricultura do Paraná (SEAB). The authors wish to thank SEAB veterinarians for their field work, Otilia Bento,
Valeria Natasha Teixeira and Segismundo Sarnoski and Luciane Hennig for their technical assistance. We thank Dr. Flávio Echevarria for providing the RESO program.

\section{RESUMO}

O teste de redução da contagem de ovos de helmintos por grama de fezes (FECRT) foi usado para testar a eficiência dos antihelmínticos em 42 propriedades produtoras de ovinos, em cinco diferentes regiões no Estado do Paraná, Brasil. O estudo foi realizado entre Julho 1996 a Julho de 2000. Foram avaliados animais com infecção natural. Cinco drogas foram usadas só ou em combinação (benzimidazole, imidazothiazole, ivermectin, milbemicina e closantel). Resultados mostraram que a prevalência de resistência foi alta para todos os antihelmínticos avaliados: $88.1 \%$ para benzimidazoles (oxfendazole), $78.6 \%$ para ivermectin, $56.4 \%$ para closantel, $38.7 \%$ para closantel + oxfendazole, $38 \%$ para levamisole, e $23.6 \%$ para moxidectin. Havia resistência múltipla em todas fazendas estudadas. Na identificação das larvas de helmintos recuperadas das culturas de fezes após o tratamento verificou-se que maioria pertenciam a Haemonchus sp. e Trichostrongylus sp. O fracasso das drogas existentes no mercado em combater a verminose é considerado um assunto importante. No presente artigo algumas sugestões são discutidas para melhorar a situação, elas incluem uma mudança de atitude em relação ao uso indiscriminado de antihelmínticos.

\section{REFERENCES}

Coles, C. G.; Bauer, C. and Borgsteede, F. H. M. (1992), World Association for the advancement of Veterinary Parasitology W. A. A. V. P. Methods for the detection of anthelmintic resistance in nematodes of a veterinary importance. Vet. Parasitol., 44, 44-35.

Cunha Filho, L. F. C.; Luz Pereira, A. B. and Yamamura, M. H. (1998), Resistance a antihelmínticos em ovinos na região de Londrina-ParanáBrasil, Semina, 19, 31-37.

Dash, K. M.; Newman, R. L. and Hall, E. (1985), Recommendations to minimize selection in anthelmintics resistance in nematode control programs. In: Anderson, N. and Waller, J. P. (eds.). Resistance in Nematodes to Anthelmintic Drugs, $J$. CSIRO, Division of Animal health. Glebe, NSW, Melbourne, Australia. pp. 107-116. 
Echevarria, F. A. M.; Armour, J.; Bairden, K. and Duncan, J. L. (1993), Laboratory selection for ivermectin resistance in Haemonchus contortus. Vet. Parasitol., 49, 265-270.

Echevarria, F. A. M.; Borba, M. S. F.; Pin heiro, A. C.; Waller, P. J. and Hansen, J. W. (1996), The prevalence of anthelmintic resistance in nematode parasites of the sheep in Southern Latin America: Brazil. Vet. Parasitol., 62, 199-206.

Echevarria, F. and Pinheiro, A. C. (1989), Evaluation of anthelmintic resistance in sheep flocks in the municipality of Bagé, Rio Grande do Sul. Pesq. Vet. Brasileira, 9, 147-148.

Echevarria, F. and Trindade, G. N. P. (1989), Anthelmintic resistance by Haemonchus contortus to ivermectin in Brazil: A preliminary report. Vet. Rec., 124, 147-149.

Eddi, C; Carascostantogolo, J; Peña, M.; Waller, P. J. and Hansen, J. W. (1996), The prevalence of anthelmintic resistance in nematode parasites of the sheep in Southern Latin America: Argentina. Vet. Parasitol., 62, 187-189.

Farias, M. T.; Bordin E. L.; Forbes A. B. and, Newcomb K. (1997), A survey on resistance to anthelmintics in sheep stud farms of southern Brazil. Vet. Parasitol.,72, 209-214.

Instituto Agronômico do Paraná (1994), Cartas Climáticas do Estado do Paraná. 49 pp.

Maciel, S.; Giménez, A. M.; Gaona, C.; Waller, P. J. and Hansen, J. W. (1996), The prevalence of anthelmintic resistance in nematode parasites of the sheep in Southern Latin America: Paraguay. Vet. Parasitol., 62, 207-211.

Nari, A.; Salles, J.; Gil, A.; Waller, P. J. and Hansen, J. W. (1996), The prevalence of anthelmintic resistance in nematode parasites of the sheep in Southern Latin America: Uruguay. Vet. Parasitol., 62, 213-222.

Perez, J. R. (1932), As verminoses dos nossos rebanhos. In: Congresso Rural (6.: Porto Alegre, 1932). Porto Alegre, Brasil, Typographia Gundlach. pp. 408-414.

Prichard R. K. (1990), Anthelmintic resistance in nematodes: extent recent understanding and future directions for control and research. Int. J. Parasit., 20, 515-523.

Roberts and O'Sullivan (1950), Methods for egg counts and larval cultures for strongyles infecting. Aust. J. Agric. Res., 1 : (1), 99-102.

Sangster N. C. (1999), Anthelmintic resistance: past, present and future. Int. J Parasitol., 29, 115-124.

Soccol, V. T.; Sotomaior, C.; Souza, F. P. and Castro, E. A. (1996), Occurrence of resistance to anthelmintics in sheep in Paraná State, Brazil. Vet. Rec., 139, 421-422.

Souza, A. P.; Belato, V. and Ramos, C. I. (1993), Resistência do Haemonchus contortus ao ivermectin e ao albendazole. In: Proc. 8. Seminário Brasileiro de Parasitologia Veterinária, H-21.
Vieira, L. S.; Berne, M. E. A.; Cavalcante, A. C. R. and Costa, C. A. F. (1992), Haemonchus contortus resistance to ivermectin and netobimin in Brazilian sheep. Vet. Parasitol., 45, 111-116.

Waller, P. J.; Echevarria, F.; Eddi, C.; Maciel, S.; Nari, A. and Hensen, J. W. (1996), The prevalence of anthelmintic resistance in nematode parasites of the sheep in Southern Latin America: General overview. Vet. Parasitol., 62, 181-187.

Zajacc, A. M. and Gipson, T. A. (2000), Multiple anthelmintic resistance in a goat herd. Vet. Parasitol., 87, 163-172.
Received: February 13, 2003; Revised: May 07, 2003; Accepted: August 13, 2003. 